\title{
LONG LINE CLIFF TOPOGRAPHY MEASUREMENT BY USING STRUCTURE FROM MOTION ALGORITHM IN PHOTOGRAMMETRY
}

\author{
C. Altuntas ${ }^{1, *}$ \\ ${ }^{1}$ Konya Technical University, Engineering and Natural Science Faculty, 42075 Selcuklu Konya, Turkey - caltuntas@itu.edu.tr
}

Commission II

KEY WORDS: Cliff Topography, Digital Elevation Model, Georeferencing, Photogrammetry, Long Line Measurement, Ground Control Point

\begin{abstract}
:
The topography of cliffs and steep slopes must be measured to acquire additional information for landscaping, visualizing changes and taking precautions against natural hazards. The Earth topography has been measured predominantly with photogrammetry, terrestrial/aerial laser scanning or other traditional measurement techniques. The stereo photogrammetry necessitates greater effort to obtain a three-dimensional (3D) model of the imaged surface. Meanwhile, terrestrial or aerial laser scanning can collect high-density measurements of spatial data in a short time. However, the costs of implementing laser scanning instruments are very high. Furthermore, conventional measurement techniques that use total stations require immense effort to collect complete $3 \mathrm{D}$ measurements of cliffs. On the other hand, dense image based point cloud using multi-view photogrammetry based on structure from motion ( $\mathrm{SfM}$ ) algorithm is much more effective than the others for measuring the Earth topography. In this study, the cliff topography of an old quarry located in the state of Selcuklu of Konya Province in Turkey was measured by multi-view photogrammetry. The cliff has a continuous length of approximately 600 metres and a height of 25 metres in some places. The 3D model of the cliff was generated with the image based dense point cloud of multi-view photogrammetry. Then 3D dense point cloud model was registered into a local georeference system by using control points (CPs). Because of the long line measurement area, number and localization of the CPs is very important for achieving a high-accuracy to registration into georeferenced system. The registration accuracies were evaluated for different number and distribution of the CPs with the residuals on the check points (ChPs). The high accuracy registration was acquired with uniform distributed 3 and 8 CPs as the residuals of $24.08 \mathrm{~cm}$ and $23.03 \mathrm{~cm}$ on the ChPs respectively. The results indicated that 3D measurement of long line cliffs can be performed using multi-view photogrammetry, and the registration should be made with the uniform distributed CPs. In addition, a texture-mapped 3D model and orthophoto images of the cliff surfaces were created for detailed visualization.
\end{abstract}

\section{INTRODUCTION}

Cliffs and steep slopes can be formed throughout coastal landscapes, roads, open mines, quarries and landslide areas. They can exceed fifty metres in height in some places. Land management and planning studies require measurements of the topography of cliffs together with the terrain to conduct threedimensional (3D) modelling of the Earth's surface. In addition, cliffs should be imaged during particular periods to take precautions for natural hazards that arise from them. Thus, it is important that cliff measurement methods are low-cost and easy to use.

Cliffs can be modelled with photogrammetry, laser scanning or traditional measurement techniques. The changes throughout coastal landscapes have been imaged with aerial photogrammetry (Moore et al., 1999; Hapke,and Richmond, 2000; Warrick et al., 2017). There are many restrictions, such as visualization limitations and large amounts of requisite labour, when measuring cliffs with photogrammetry. Wangensteen et al. (2007) recorded images of coastal cliffs during a particular period to create a 3D model. The measurements had been carried out with an accuracy of $10 \mathrm{~mm}$ as determined by photogrammetric evaluation. Small changes with a size of $3 \mathrm{~mm}$ along the cliff were also imaged by photogrammetry. In other studies, cliffs with hazardous topographies were measured by close-range photogrammetry and terrestrial laser scanning, and the results were compared (Brideau et al., 2012; Tannant, 2015). Both methods have similar degrees of accuracy, but it was noted that photogrammetry provides low-cost measurements. In this manner, the erosion of glacier cliffs was detected by photogrammetry (Winkler et al., 2012); in that study, the images were conjugated using key points, and multiview photogrammetry was evaluated as the proper measurement method for glacier cliffs.

Terrestrial laser scanning has also been used for measuring the topographies of cliffs. The cliffs along coastal landscapes have been measured and modelled through laser scanning (Olsen et al., 2009; Poulton et al., 2006). The registration and georeferencing of measured data from very long coastal landscapes have been performed with ground control points that were measured based on a global positioning system. Meanwhile, Abellan et al. (2011) and Whitworth et al. (2006) measured the topographies of cliffs and steep slopes using terrestrial laser scanning in order to detect the changes in the cliff topography. In addition, the cliff in an excavation area was also imaged through laser scanning (Warden et al., 2007). Albea and Scaioni (2010) also exploited terrestrial laser scanning to image the changes in the cliff topography. On the other hand,

* Corresponding author 
aerial laser scanning has been frequently used for creating digital elevation model of the earth surface (Wang and Tseng, 2014). The comparison of terrestrial and aerial laser scanning has shown that relatively small changes in the face of seacliff are reliable detected only with more accurate by terrestrial laser scanning. However the airborn system can rapidly survey long cliff lengths (Young et al., 2010). Furthermore, cliffs can be measured using a total station device for traditional measurement methods. Such conventional triangulated measurements require more time. Thus, they do not have the capability to represent the cliff shape with a sufficient amount of points. The measurement conditions and costs may restrict the exploitation of these measurement techniques to conduct 3D modelling of cliffs. However, dense point clouds have been created from images by multi-view photogrammetry for $3 \mathrm{D}$ modelling of topography of the Earth's surface (Previtali et al., 2014) and of objects (Barazzetti et al., 2010).

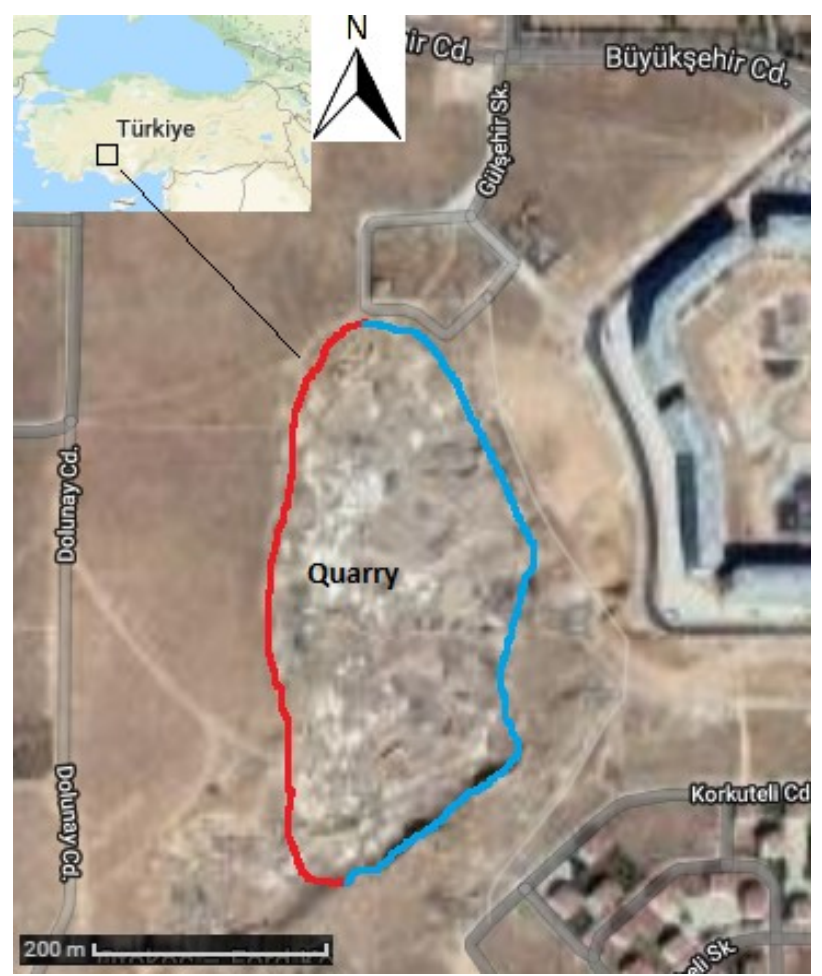

Figure 1. Geographical position of the study area (Latitude:

37o.58'13". 18 N, Longitude: 37o. 30'07' E). Red line shows measured cliff on border of the quarry. (Image is from Google Maps)

In this study, the cliffs at the edge of a quarry located in the state of Selcuklu of Konya Province were measured by using the SfM photogrammetry method. The quarry had previously been located on the outskirts of the city, but it has been surrounded by buildings (Figure 1). The quarry is not using since, but plans are in place to redesign it into an esplanade and resort. The recreational design of this quarry area requires measurements of the cliffs along its edge. Accordingly, the hazardous places where stones can fall must be taken into consideration while preparing the abovementioned design plans. The cliff is 600 metres long and 25 metres high in some places (Figure 2). A 3D model of the cliff was generated with a dense point cloud that was created through multi-view photogrammetry. The $3 \mathrm{D}$ model was then registered to a local geodetic coordinate frame with control points (CPs). The accuracy of the registration results was analysed with residuals at the check points (ChPs). The number and distribution of the CPs affect the accuracy of georeferencing. In addition, the registration of measurement data of long line corridor such as the cliff in this study should be made with suitable number and location of the CPs. Thus the accuracy of the registration was evaluated with many configurations of the CPs to finding the best. In addition to this, texture mapped 3D model and orthophotos were created for visualizing topography of the cliff. The rest of the paper was organized as 5 sections. The information about data acquisition was given in Section 2, image based point cloud creation methodology was explained in Section 3, results of the study were given in Section 4, and the finally scientific discussion and conclusion were given in Section 5 and Section 6 respectively.

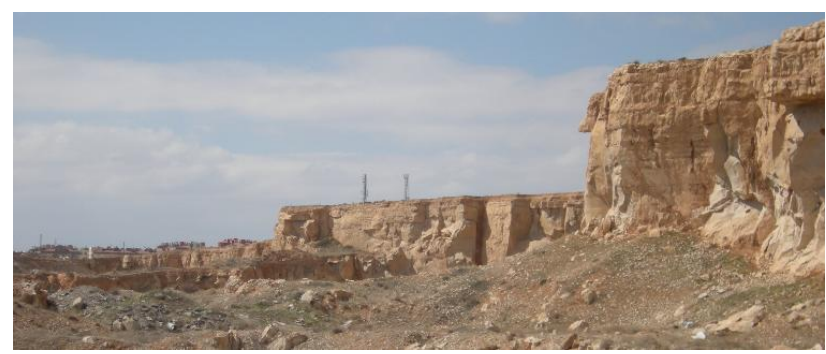

Figure 2. An image from the quarry cliff

\section{DATA ACQUISITION}

The cliff line was imaged with 305 images as stereoscopic mode in a single column. The images were recorded with a Nikon Coolpix P50 camera, which has a $3264 \times 2448$ pixel array, a 4.7$\mathrm{mm}$ focal length and a $1.78 \times 1.78$ micron pixel size. Every image covers an area greater than the cliff height. 11 CPs and 9 ChPs were located at the base of the cliff (Figure 3). Their locations on the images do not have a negative effect on the registration into the local geodetic coordinate system because almost all of the images cover a large area at the base of the quarry together with the entire height of the cliff. The $\mathrm{Y}$ axis of the local coordinate frame was oriented parallel to and along the line of the cliff, the $X$ axis was oriented perpendicular to the cliff surface, and the $\mathrm{Z}$ axis was oriented vertically. The coordinates, which are based on the local frame, were measured with a Topcon ES 102 total station with the capability to acquire reflectorless measurements at a range of up to $200 \mathrm{~m}$ with a $(3+2 \mathrm{ppm} * \mathrm{D}) \mathrm{mm}$ accuracy (Topcon, 2018). The total station is use phase difference method to measuring distance D from instrument to object.

\section{SfM ALGORITHM}

The photogrammetry derives three-dimensional measurement data from two-dimensional stereoscopic images. Multi-view photogrammetry uses a technique referred to as SfM to resolve feature positions within a defined coordinate system (Peterson et al., 2015). SfM refers to a set of algorithms that includes the automatic detection and matching of features across multiple images. The camera parameters, image positions and 3D geometry of a scene are automatically determined by an iterative bundle adjustment. The photogrammetry with SfM procedure is called many different names, including multi-view photogrammetry, dense point cloud extraction, and dense image matching. Thanks to its easy application, multi-view photogrammetry has been used in a wide variety of applications that require $3 \mathrm{D}$ spatial data. 
All amateur camera images can be used to creating a dense point cloud by using multi-view photogrammetry. Furthermore, mobile phones and other sources of imagery can also be used for this purpose. Most of the multi-view photogrammetry softwares are able to calibrate a camera and create a 3D point cloud. Hence, this procedure does not require the camera to be pre-calibrated.

The creation of a dense point cloud is performed in three steps. At the first step, the SIFT, ASIFT and SURF operators in addition to other similar key point detectors are used to create key points from the images. These operators locate key points without being affected by the scale, rotation or brightness of the images. The second step is to estimate the relative position of the images by matching similar key points among all of the images. By considering a simple image pair, the disparity (i.e., the parallax due to horizontal motion) is inversely proportional to the distance between the camera and the object. The automated measurement of such a disparity by establishing dense and accurate correspondences among images is a challenging task (Remondino et al., 2013). The matching results are generally sparse point clouds, which are then used as seeds to grow additional matches. The third step is to create a dense point cloud. Coordinates are generated for every matched point from all of the conjugated images. Currently, all available algorithms focus on dense reconstructions using stereo or other multi-view approaches. The scale provides real-world measurements of the created dense point cloud model. Generated ground CPs allow us to attain a scale for the 3D point cloud model and register it to a local or global reference coordinate system. However, the scale can be set to a model using the ratio of the distance from the real world and a $3 \mathrm{D}$ dense point cloud model.

\section{RESULTS}

\subsection{Camera Calibration}

The camera that was used to collect the images was not calibrated before processing the images. The calibration parameters were estimated together with the image alignment during the SfM process. In addition, the pre-calibration of the camera was performed with a PhotoModeler calibration sheet, which has known control points. The Photomodeler estimates camera calibration parameters with the calibration sheet images taken from different point of view angles. The calibration parameters having been estimated both pre-calibration using PhotoModeler and SfM process using PhotoScan (Agisoft, 2017) are given in Table 1 . The pre-calibration is generally performed converging images taken from ideal point of view angles. However, the images in creating dense point cloud may not be existed in convenient positions. Nevertheless, there are any significant differences between the calibration results on Table 1. Thus SfM self-calibration results were used during the creation of dense point cloud.

\begin{tabular}{|l|l|l|}
\hline & Agisoft PhotoScan & $\begin{array}{l}\text { PhotoModeler (Pre- } \\
\text { calibration) }\end{array}$ \\
\hline $\begin{array}{l}\text { Focal } \\
\text { length(f) }\end{array}$ & $\begin{array}{l}2700.86 \text { pixel } \\
(4.7 \mathrm{~mm})\end{array}$ & $\begin{array}{l}2700.68 \text { pixel } \\
(4.52 \mathrm{~mm})\end{array}$ \\
\hline Pp x & -32.7038 pixel & -25.7623 pixel \\
\hline Pp y & 3.83057 pixel & 15.539 pixel \\
\hline $\begin{array}{l}\text { Pixel } \\
\text { dimension }\end{array}$ & $1.78 \times 1.78 \mu \mathrm{m}$ & $1.67 \times 1.67 \mu \mathrm{m}$ \\
\hline K1 & -0.117029 & 0.006056 \\
\hline
\end{tabular}

\begin{tabular}{|l|l|l|}
\hline K2 & 0.0314133 & $-7.095 \mathrm{e}-05$ \\
\hline P1 & 0.000136845 & -0.000126 \\
\hline P2 & -0.000623995 & -0.000101 \\
\hline
\end{tabular}

Table 1 . The estimated camera calibration values

\subsection{Point Cloud Measurement Data}

The detection of key points and their matching among all of the images token 42 minutes. All of the images were matched with 351218 conjugated key points, 313851 of which were evaluated as correct. The structuring of the images took an estimated 11 minutes. After the image alignments, sparse point clouds were created by computing $3 \mathrm{D}$ coordinates for every matched key point using image triangulation. Some of the information about the conjugated images and the created sparse point clouds are given in Table 2. After the image structures were estimated, a dense point cloud model with 15.5 million points was created in 1 hour 33 minutes.

\begin{tabular}{|l|l|}
\hline Images\# & 331 \\
\hline Flaying altitude & 31.9 meters \\
\hline Ground resolution & $9.5 \mathrm{~mm} /$ pixel \\
\hline Coverage area & 0.0199 square meters \\
\hline Tie points\# & 313851 of 351218 \\
\hline Projections & 939411 \\
\hline Reprojection error & 0.734 pixel \\
\hline Max. reprojection error & 27.69 pixel \\
\hline
\end{tabular}

Table 2. Project data and sparse point cloud creation results

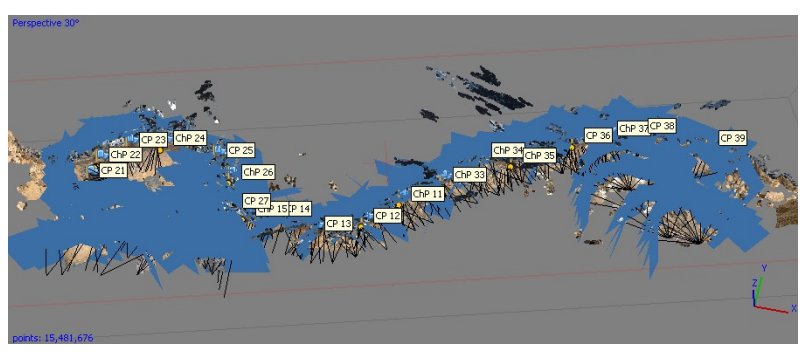

Figure 3. Imaging locations, CPs and ChPs of the cliff measurement

\subsection{Georeferencing}

The arbitrary registration of a large number of end lab (forward) stereoscopic images results in cumulative registration errors. Therefore, both the numbers and the distributions of CPs are crucial for controlling these registration errors. The registration to the local geodetic frame was performed with different configurations of CPs. The accuracy of the registration was evaluated using the residuals on the ChPs (Figure 4, Figure 5).

$$
\begin{gathered}
d_{x}=X_{m}-X_{\varepsilon} \\
d_{y}=Y_{m}-Y_{\varepsilon} \\
d_{z}=Z_{m}-Z_{\varepsilon} \\
d_{x y z}=\sqrt{\left(X_{m}-X_{e}\right)^{2}+\left(Y_{m}-Y_{E}\right)^{2}+\left(Z_{m}+Z_{E}\right)^{2}}
\end{gathered}
$$

Where $d_{x y}$ is the error on the XY plane and $d_{x y z}$ is the 3D spatial error. The subscripts $m$ and $e$ represent measured and estimated coordinates, respectively. Although all of the CPs and ChPs imaged into average nine images, they were manually selected from three or four images. The same nine ChPs were used to evaluating the registration accuracy for all the CPs 
configurations. The estimated residuals on the ChPs indicate that the uniformly distributed CPs have a high accuracy of registration (Table 3). The overall accuracy of the registration was evaluated by the root mean square error (RMSE) about the coordinate residuals and the spatial errors on the XY plane and the XYZ coordinate space.

$$
\begin{gathered}
\text { RMSE }_{d_{x}}=\sqrt{\frac{\sum\left(d_{x}\right)^{2}}{n}}, \text { RMSE }_{d_{y}}=\sqrt{\frac{\sum\left(d_{y}\right)^{2}}{n}}, \\
\text { RMSE }_{d_{z}}=\sqrt{\frac{\sum\left(d_{z}\right)^{2}}{n}} \\
\text { RMSE }_{\mathbb{d}_{x y}}=\sqrt{\frac{\sum\left[d_{x}\right)^{2}+\sum\left(d_{y}\right]^{2}}{n}} \\
\text { RMSE }_{d_{x y z}}=\sqrt{\frac{\sum\left(d_{x}\right)^{2}+\sum\left(d_{y}\right)^{2}+\sum\left(d_{z}\right)^{2}}{n}}
\end{gathered}
$$

Where, $n$ is number of the ChPs, and it is nine for all configurations of the CPs.

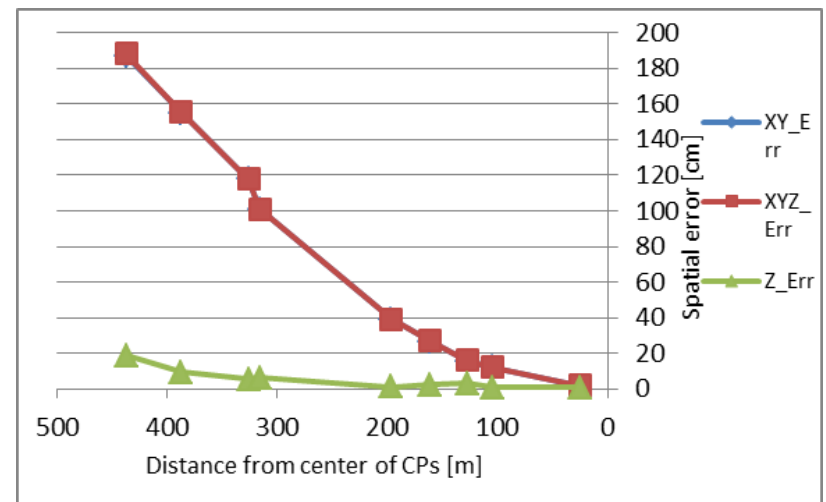

a)

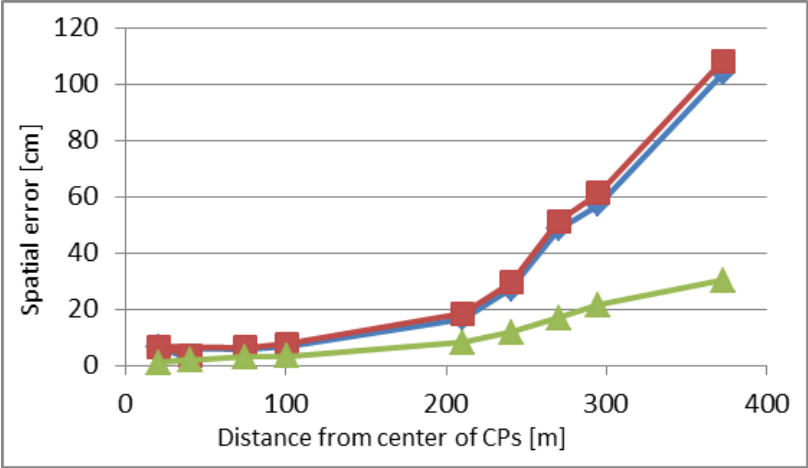

b)

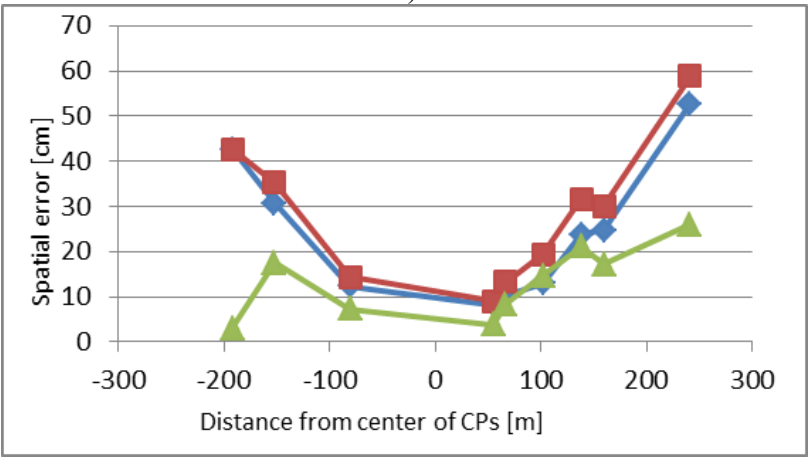

c)

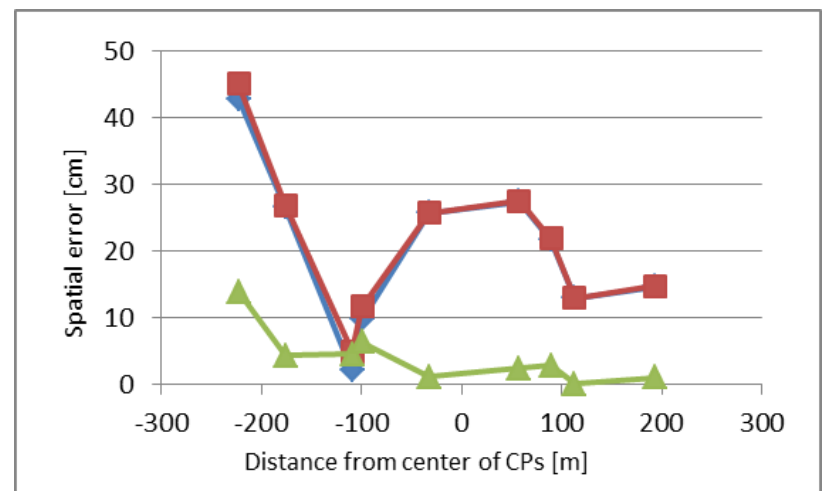

d)

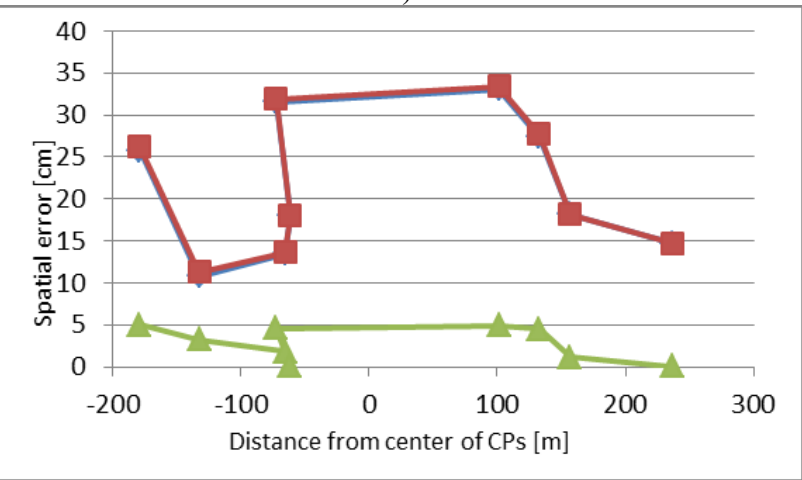

e)

Figure 4. The ChPs error estimation after registration with a) 3 CPs clustered on the north, b) 3 CPs clustered on the south, c) 3

CPs clustered on the middle, d) 3 CPs uniform, e) 8 CPs uniform. The figures have the same ordinary ChPs as the name of $22,24,26,15,11,33,34,35,37$ form south to north (left to right)
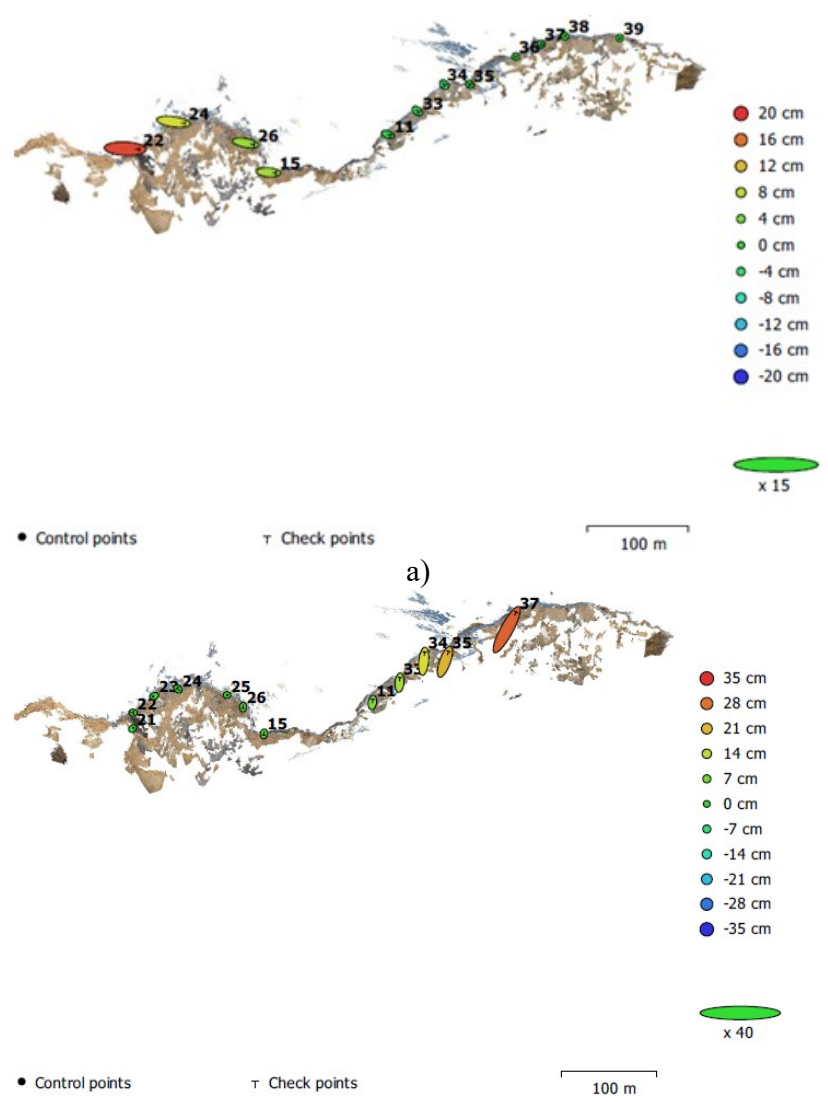

b) 


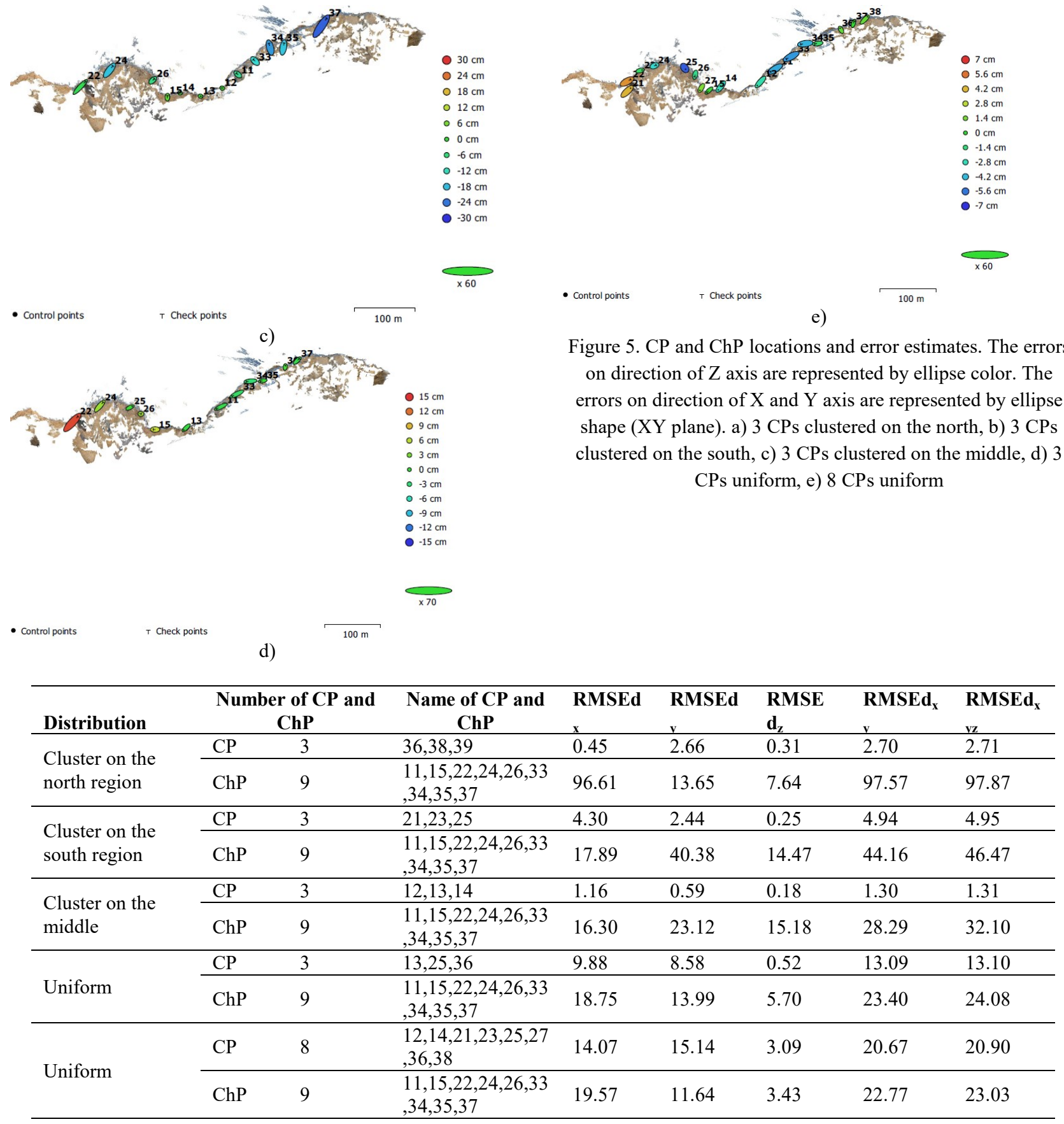

Table 3. According to different combination, RMSE of residuals on CPs and ChPs [units: $\mathrm{cm}$ ].

\subsection{Visualization}

A digital elevation model was created according to the reference surface composed of the XY axes. The cliff heights on the XY plane correspond to the differences between $\mathrm{Z}$ axis coordinates (Figure 6). A texture-mapped 3D model and an orthomosaic photo were also generated for the entire cliff surface (Figure 7). The image quality and perspective-induced distortions both affect the brightness and sharpness of the texture-mapped 3D model. Thus, the images were acquired under sunny conditions when the cliff was not in shadow. The proper images for texture mapping can be selected with an interactive- or optimizationbased camera network design (Alsadik et al., 2013). In this study, since the cliff surface had been imaged with large overlapping photos, the texture data were mapped onto a mesh surface composed of triangles from the images selected by the PhotoScan software. The cliff height was measured from the 3D model (Figure 7), and contour lines were created to display the topography of the cliff surface (Figure 8). 

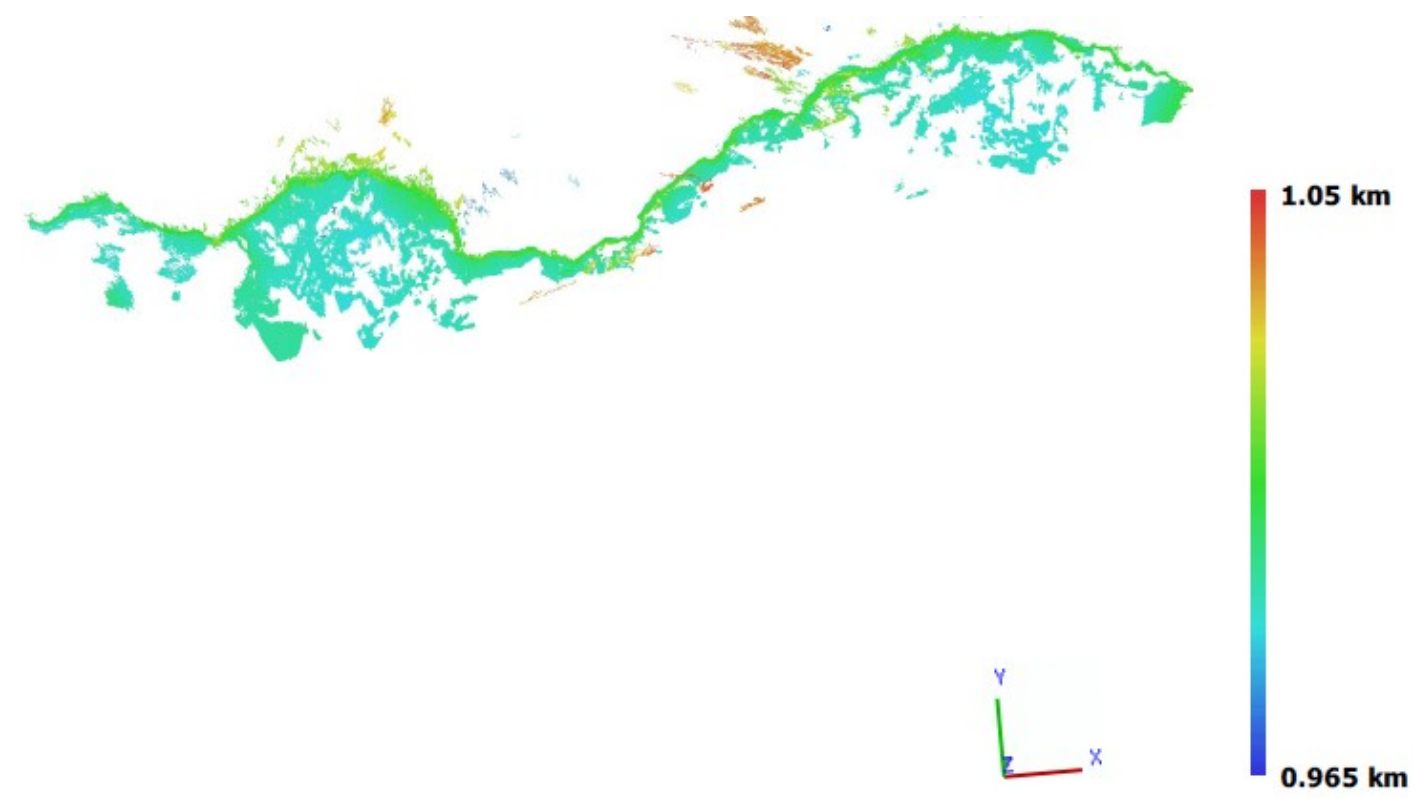

$100 \mathrm{~m}$

Figure 6. Digital elevation model according to XY reference plane

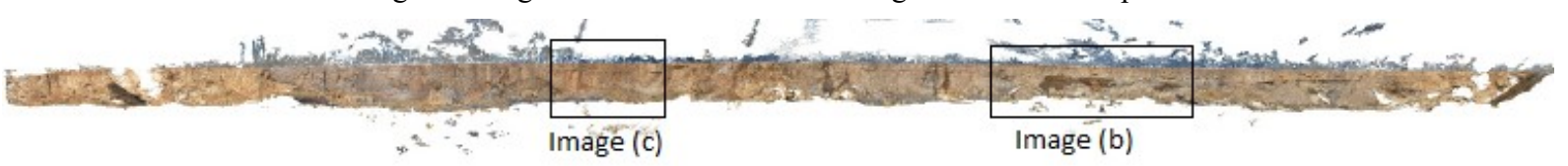

(a)

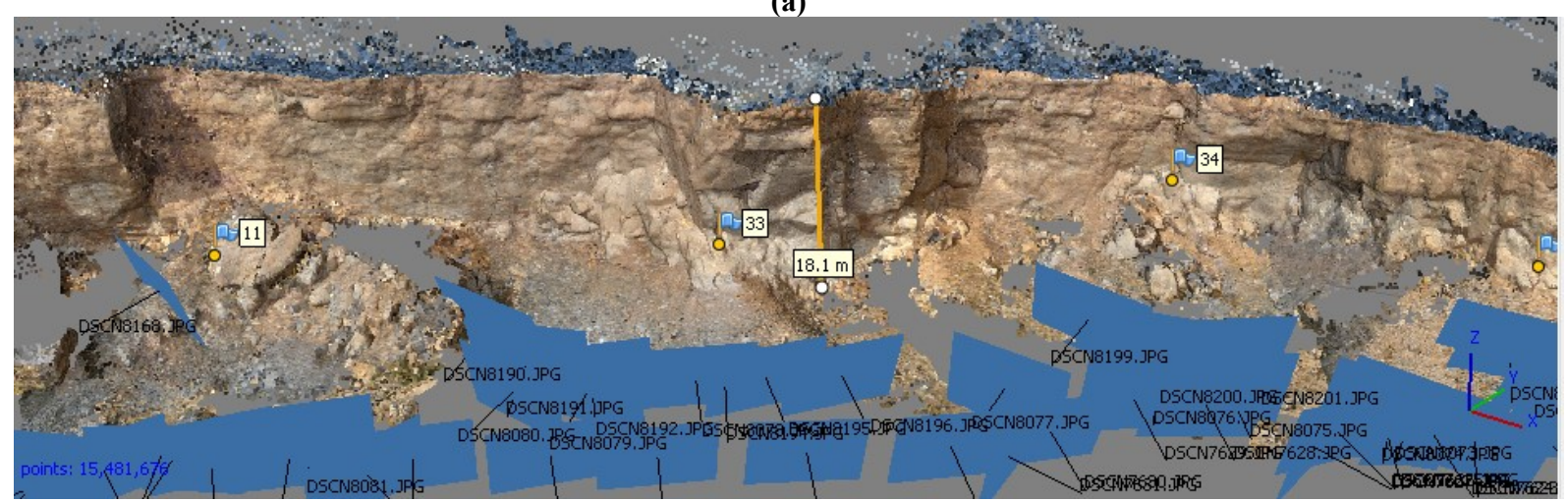

(b)

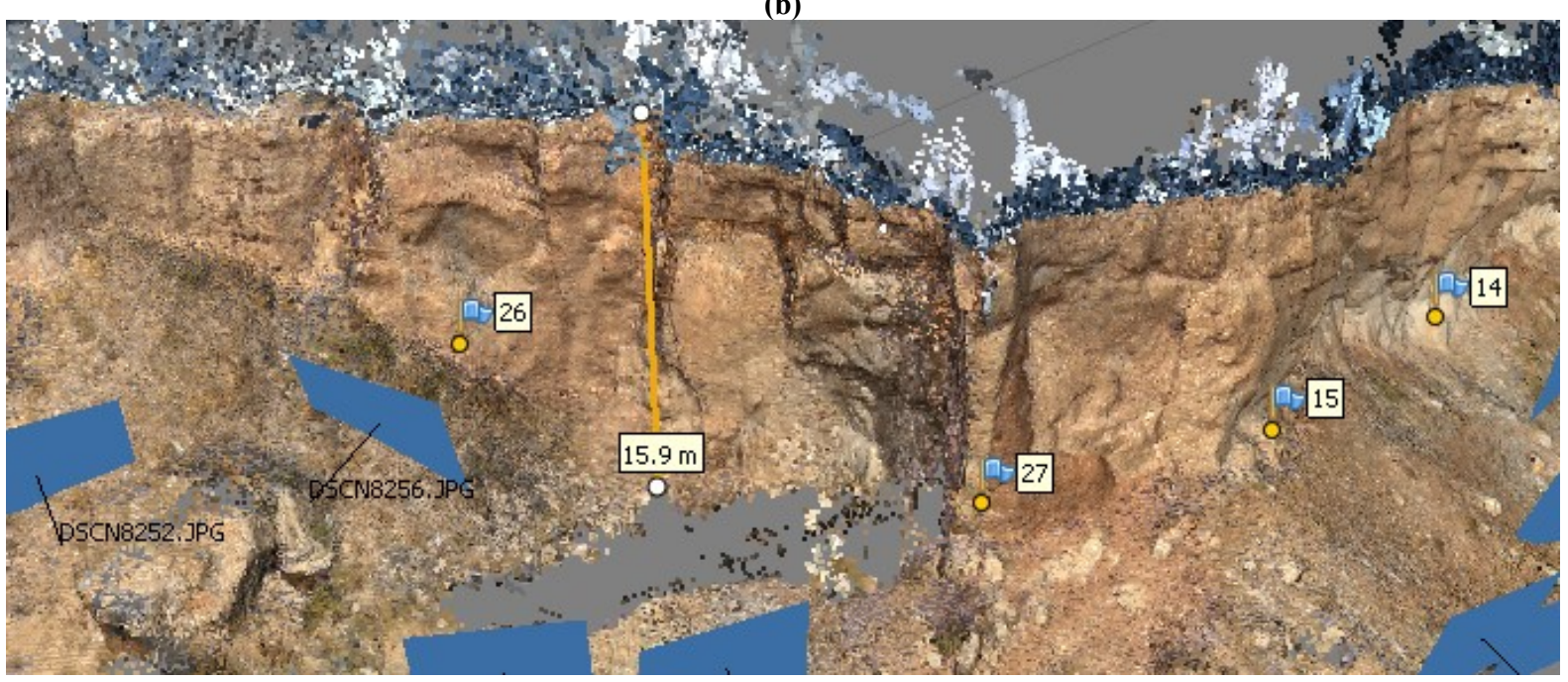

(c)

Figure 7. a) Orthomosaic image, b) and c) height measurement on the cliff 


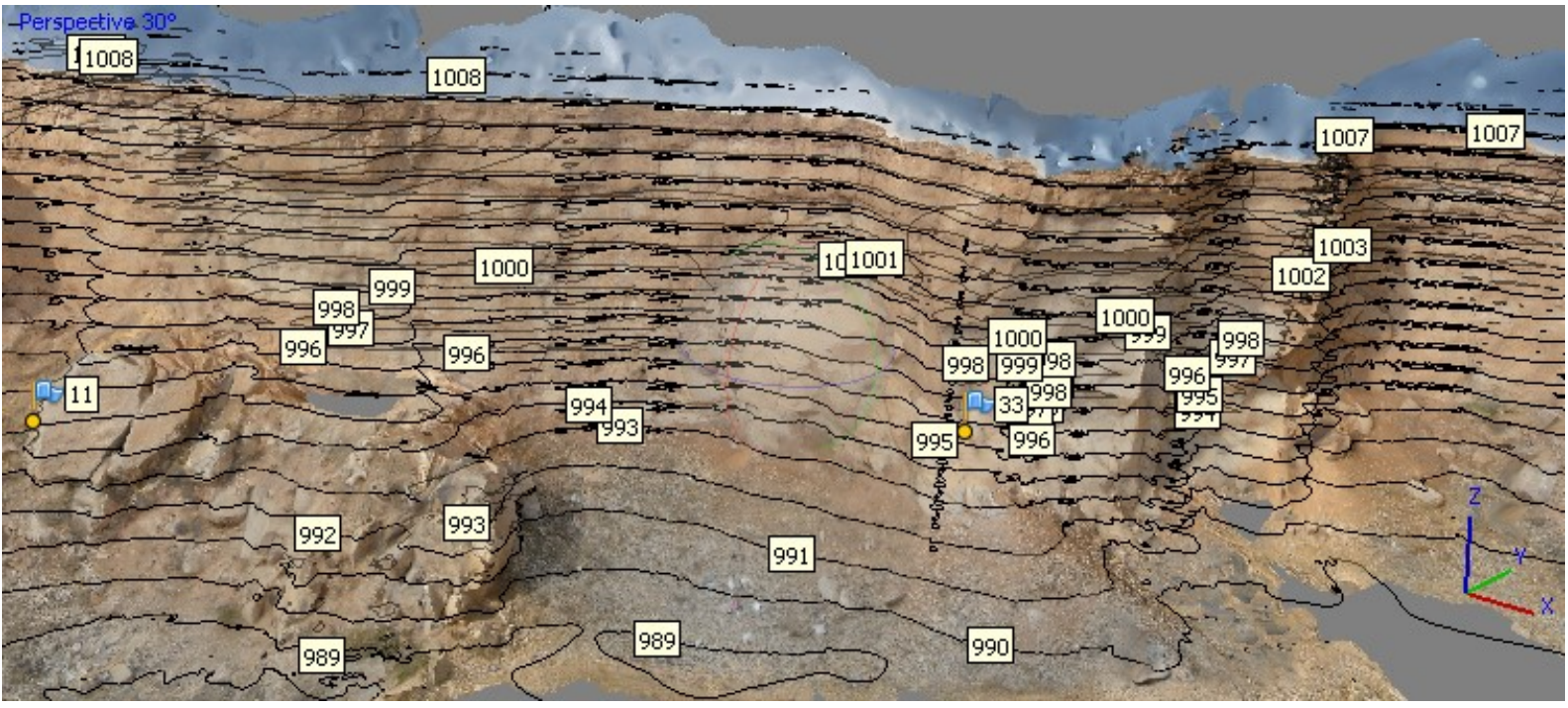

Figure 8 . The cliff topography and height representation by contour line with one meter intervals

\section{DISCUSSION}

The internal camera calibration parameters were estimated while aligning the photos with PhotoScan. This process does not need the use of artificial CPs. However, the pre-calibration of the camera is generally performed with a calibration sheet, which contains CPs with known shapes and positions. The results will exhibit any significant differences in the accuracies between the point cloud generated with pre-calibration and that generated with an on-site calibration of the camera. Therefore, image processing and measurements without pre-calibrating the camera is more practical.

The distribution and locations of the CPs will affect the accuracy of the 3D model because of the long length of the measurement area without any side overlap. The residuals on the ChPs were increased by clustering the CPs (see Table 1). If three CPs were clustered on the southern and northern regions of the cliff, the RMSEs of the residuals would reach $46,47 \mathrm{~cm}$ and $97.87 \mathrm{~cm}$, respectively. Similarly, the RMSE of the residuals on the ChPs was $32.10 \mathrm{~cm}$ with three CPs clustered at the middle. If more than three CPs are clustered in these regions, the residuals on the ChPs will decrease. Nevertheless, the residuals on the remote $\mathrm{ChPs}$ will still be high due to the length of the measurement area. However, RMSEs of $23.03 \mathrm{~cm}$ and $24.08 \mathrm{~cm}$ were achieved for the residuals on the ChPs with uniform distributions of 8 and $3 \mathrm{CPs}$, respectively. These results indicate that the CPs should be distributed uniformly to achieve a high accuracy. On the other hand, the PhotoScan software offers camera optimization to remove non-linear deformation that depends on many factors such as an overlap between neighbouring photos. Non-linear deformation will affect the accuracy of the final estimates of internal and external camera parameters. Possible non-linear deformations of the model can be removed by optimizing the created point cloud and camera parameters. PhotoScan adjusts the estimated point coordinates and camera parameters by minimizing the sum of the reprojection error and the reference coordinate misalignment error while performing this optimization. Nevertheless, this optimization did not provide the expected level of recovery for the registration accuracy of nonuniform CPs. After applying the optimization to the registration with nonuniform distributed CPs (Table 1), slight level improvements were observed in the registration accuracy. However, the registration accuracy for 3 and 8 uniformly distributed CPs was five times better than the others. The camera optimization procedure also shows that a uniform distribution of the CPs is essential for the high accuracy registration of dense point clouds from long measurement area such as that in this study.

\section{CONCLUSIONS}

Cliffs represent hazardous topographic features on the Earth's surface. The changes in the cliff topography should be checked by imaging the cliff during a special period. However, the conditions of such cliffs can restrict the ability to measure them through aerial or terrestrial LIDAR. Meanwhile, mobile mapping techniques based on aerial and unmanned aerial vehicles exhibit high costs, whereas dense point cloud measurement methods have a high accuracy and represent a practical method for acquiring the cliff topographies. However, long strips of measurement areas require the imaging stations and the locations of CPs to be planned prior to modelling via SfM photogrammetry. A large number of images were consequently taken to show all of the cliff surfaces. The exterior image orientation and dense point cloud creation were performed based on a local geodetic coordinate frame. The registration was performed with different configuration of the CPs in varying locations and numbers along the cliff. The registration accuracy of the $3 \mathrm{D}$ model was evaluated with the residuals on the ChPs. The residuals on the ChPs were estimated at $24.08 \mathrm{~cm}$ and $23.03 \mathrm{~cm}$ with 3 and 8 uniformly distributed CPs, respectively. Nonuniform distributed CPs caused high residuals and low registration accuracies. Thus, the CPs should be distributed uniform throughout the measurement area to obtain high-accuracy measurements with multi-view photogrammetry for mapping long line area such as that in this study. The number of CPs have not significant effect on the registration accuracy. The least three CPs that have uniform distribution are assure high level registration accuracy.

Many mapping studies such as power, road and coastal line include corridor measurement. On the other hand unmanned aerial platforms that enable low cost imaging support image based measurements via creating dense point cloud. The created 3D model should be registered to extensive geodetic frame by using CPs in order to connecting with the other geographical spatial data. The CPs have been localized in uniform 
distribution on the measurement area to avoiding from cumulative registration errors. The results also show that the image brightness and imaging distance from the object surface will affect the qualities of texture-mapped 3D model and orthophoto. Further study will be focused on investigating the 3D model accuracy related with imaging positions and numbers of the images.

\section{REFERENCES}

Abellan, A.; Vilaplana, J.M.; Calvet, J.; Selles, D.G.; Asensio, E., 2011. Rockfall monitoring by terrestrial laser scanning-case study of the basaltic rock face at castellfollit de la roca (Catalonia, Spain). Natural Hazards Earth Syst. Sci., 11, 829841.

Agisoft, 2017. Photoscan Professional (Version 1.3.2.4205)

Alba, M.; Scaioni, M., 2010. Automatic detection of changes and deformations in rock faces by terrestrial laser scanning. The International Archives of the Photogrammetry, Remote Sensing and Spatial Information Sciences Vol. XXXVIII, Part 5, pp. 11-16.

Alsadik, B.S.; Gerke, M.; Vosselman, G., 2013. Automated camera network design for 3D modeling of cultural heritage objects. Journal of Cultural Heritage, 14(6), 515-526.

Barazetti, L.; Scaioni, M,; Remondino, F., 2010. Orientation and 3D modelling from markerless terrestrial images: combining accuracy with automated. The Photogrammetric Record, 25(132), 356-381.

Brideau, M.A.; Massey, C.I.; Archibald, G.; Jaboyedof, M., 2012. Terrestrial Photogrammetry and LIDAR Investigation of the Cliffs Associated with the Seismically Triggered Rockfalls During the February and June 2011 Chriscurch Earthquakes, Landslides and Engineered Slopes, Taylor and Francis Group, London, ISBN: 978-0-415-62123-6, 1179-1185.

Hapke, C.; Richmond, B., 2000. Monitoring beach morphology changes using small-format aerial photography and digital softcopy photogrammetry. Environmental Geosciences, 7(1), 32-37. doi:10.1046/j.1526-0984.2000.71001.x

Moore, L.J.; Benumof, B.T.; Griggs, G.B., 1999. Coastal erosion hazards in Santa Cruz and San Diego Countries, California. Journal of Coastal Research, 81(28), 121-139.

Olsen, M.J.; Johnstone, E.; Driscoll, N.; Ashford, S.A.; Kuester, F., 2009. Terrestrial laser scanning of extended cliff sections in dynamic environments: Parameter analysis. Journal of Surveying Engineering, 135(4), 161-169.

Peterson, E.B.; Klein, M.; Stewart, R.L., 2015. Whitepaper on structure from motion (SfM) photogrammetry: Constructing three dimensional models from photography. Technical Report (ST-2015-3835-1), U.S. Department of the Interior Bureau of Reclamation Research and Development Office, 46 pages.

Poulton, C.V.L.; Lee, J.R.; Hobbs, P.R.N.; Jones, L.; Hall, M., 2006. Preliminary investigation into monitoring coastal erosion using terrestrial laser scanning: Case study at Happisburgh, Norfolk. The Bulletin of The Geological Society of Norfolk, 56, 45-64.
Previtali, M.; Barazzetti, L.; Scaioni, M., 2014. Accurate 3D surface measurement of mountain slopes through a fully automated image-based technique. Earth Science Informatics, 7(2), 109-122.

Remondino, F.; Spera, M.G.; Nocerino, E.; Menna, F.; Nex, F.; Barsanti, S.G., 2013. Dense Image Matching: Comparisons and Analyses. Proceedings of Digital Heritage International Congress (Digital Heritage), IEEE Xplore, INSPEC Acces. No: 14143692 1, pp. 47-54. doi: 10.1109/DigitalHeritage.2013.6743712

Tannant, D.D., 2015. Review of photogrammetry-based techniques for characterization and hazard assessment of rock faces. Int Journal of Geohazards and Environment, 1(2), 76-87.

Topcon, 2018. http://www.topcon.co.jp/en/positioning/ products/pdf/ES_E.pdf [acc.12 March 2018]

Wang, C.K.; Tseng, Y.H., 2014. Dual-directional profile filter for digital terrain model generation from airborne laser scanning data. Journal of Applied Remote Sensing, 8, 083619. doi: 10.1117/1.JRS.8.083619

Wangensteen, B.; Eiken, T.; Odegard, R.S.; Sollid, J.L., 2007. Measuring coastal cliff retreat in the Kongfjorden Area, Svalbard, using terrestrial photogrammetry. Polar Research, 26, 14-21. https://doi.org/10.1111/j.1751-8369.2007.00002.x

Warden, R.B.; Burt, R.; Briaud, J.L.; Everett, M., 2007. Laser scanning for historical and geotechnical studies at Pointe Du Hoc. The International Archives of the Photogrammetry, Remote Sensing and Spatial Information Sciences, Vol. XXXVI-5/C53, 6 pages.

Warrick, J.A.; Ritchie, A.C.; Adelman, G.; Adelman, K.; Limber, P.W., 2017. New techniques to measure cliff change from historical oblique aerial photographs and structure-frommotion photogrammetry. Journal of Coastal Research, 33(1), 39-55.

Whitworth, M.; Giles, D.; Anderson, I., 2006. Terrestrial laser scanning for applied geoscience studies in the urban environment. The Tenth IAEG Congress - Nottingham, 6-10 September.

Winkler, M.; Pfeffer, M.T.; Hanke, K., 2012. Klimanjero ice cliff monitoring with close range photogrammetry. The International Archives of the Photogrammetry, Remote Sensing and Spatial Information Sciences, Vol. XXXIX-B5, 441-446.

Young, A.P.; Olsen, M.J.; Driscoll, N.; Flick, R.E.; Gutierrez, R.; Guza, R.T.; Johnstone, E.; Kuester, F., 2010. Comparison of airborn and terrestrial lidar estimates of seacliff erosions in Southern California, Photogrammetric Eng. And Rem. Sens, 76(4), 421-427. 